\title{
Pharmacokinetic Study of Amoxicillin Capsule in Healthy Bangladeshi Subjects using Urinary Excretion Data
}

\author{
Md. Ashik Ullah ${ }^{1}$, Mohammad Abul Kalam Azad ${ }^{2}$, Rebeka Sultana ${ }^{1}$, \\ Eva Rahman Kabir ${ }^{2}$, A. H. M. Mahbub Latif ${ }^{3}$ and Abul Hasnat ${ }^{1}$ \\ ${ }^{1}$ Department of Clinical Pharmacy and Pharmacology, Faculty of Pharmacy, University of Dhaka, \\ Dhaka-1000, Bangladesh. \\ ${ }^{2}$ Department of Pharmaceutical Technology, Faculty of Pharmacy, University of Dhaka, \\ Dhaka-1000, Bangladesh. \\ ${ }^{3}$ Institute of Statistical Research and Training, University of Dhaka, Dhaka-1000, Bangladesh.
}

\begin{abstract}
The aim of the study was to compare the urinary excretion data and bioavailability of two $500 \mathrm{mg}$ amoxicillin capsules formulations in healthy Bangladeshi subjects under fasting condition and evaluate the ethnic variations in drug disposition. Twenty-four subjects were enrolled into this single-dose, randomized, open-label, twoway cross over study. A washout period of one week was allowed between two treatments. Following oral administration, urine samples were collected at different time intervals and were analyzed using a validated HPLC method with UV detection. The pharmacokinetic parameters for two formulations were calculated by noncompartmental method using the software Kinetica and statistical analysis was done for the evaluation of bioequivalence. The pharmacokinetic analysis indicated that the kinetic disposition of two formulations was similar. This was evident when the mean ( \pm standard deviation) values of the various pharmacokinetic parameters were compared. No significant difference between two formulations was found when analyzed by paired t-test and ANOVA. Therefore it can be concluded that the test product $\left(\mathrm{SK}-\mathrm{mox}^{\circledR}\right)$ is bioequivalent to the reference product $\left(\right.$ Amoxil-Bencard $^{\circledR}$ ) based on the US FDA's regulatory definition. Moreover, an ethnic variation was observed following $64.34 \%$ cumulative urinary recovery of amoxicillin over 12 hours when compared with other studies.
\end{abstract}

Key words: Amoxicillin, pharmacokinetics, Bangladeshi subjects.

\section{INTRODUCTION}

Amoxicillin, a well-known amino-substituted penicillin, enjoys widespread clinical use, not only because of its broad antibacterial spectrum but also because of its high oral bioavailability $(>90 \%)$, which makes it relatively unaffected by food or by other concomitantly administered drugs. ${ }^{1}$ The pharmacokinetics of amoxicillin has been extensively investigated, and the observed data indicate that an

Correspondence to:

Abul Hasnat

Phone: $+880-2-9661920-73$ Extn. 8164 or 008802-8612069

Fax: 880-2-8615583

E-mail: ahasnat99@yahoo.com

Dhaka Univ. J. Pharm. Sci. 8(1): 53-59, 2009 (June) oral dose of $500 \mathrm{mg}$ produces peak plasma concentration of about $10 \mu \mathrm{g} / \mathrm{ml}$ within 1 to $1.5 \mathrm{~h}$, reaches adequate therapeutic concentrations in pleural, synovial, and ocular fluids, and accumulates in the amniotic fluid, but penetrates poorly into the central nervous system unless inflammation is present. $^{2}$ Excretion of amoxicillin is predominantly renal, and $75 \%$ of an intravenous dose is recovered in the urine within $6 \mathrm{hr}$, leading to very high urinary concentrations. ${ }^{3-5}$ The drug's terminal half-life $\left(t_{1 / 2}\right)$ of elimination is 1 to $1.5 \mathrm{hr}^{2}$ Although a good number of generic oral formulations of amoxicillin are available in Bangladesh, the study on pharmaco- 
kinetic and bioavailability properties of these formulations is yet to be conducted with Bangladeshi population. Hence the current research was focused on it.

The USP 24 states that in bioequivalence studies, samples of an accessible biological fluid (blood or urine) are analyzed for drug and/or metabolite concentrations. ${ }^{6}$ Use of blood for bioequivalence study is complex. Several reports indicate that urinary excretion data of drugs can be successfully used to compare the bioavailability of different formulations. ${ }^{7}$ In order to obtain valid estimates of pharmacokinetics and bioavailability using urinary excretion data, the drug must be excreted in significant quantities in the urine and adequate sample of urine must be collected. Urinary excretion of amoxicillin is known to be almost $75 \%$ of the whole administered dose. Therefore, it will be a good method for bioavailability studies using urinary excretion data. Also, urine sampling, a non-invasive method of sampling from volunteers, may be useful for ease of compliance in recruiting volunteers to participate in bioavailability studies.

The study therefore, was conducted to investigate the pharmacokinetics and bioequivalence of $500 \mathrm{mg}$ amoxicillin capsules namely, SK-mox ${ }^{\circledR}$ as test product and Amoxil-Benacrd ${ }^{\mathbb{B}}$ as reference product using urinary excretion data in healthy Bangladeshi volunteers and also to evaluate the ethnic variation based on these pharmacokinetic parameters.

\section{MATERIALS AND METHODS}

Materials. Analytically pure amoxicillin trihydrate and cefaclor were received as gifts from Eskayef Bangladesh Ltd., Dhaka, Bangladesh. Two marketed capsule formulations, SK-mox ${ }^{\circledR}$ (manufactured by Eskayef Bangladesh Ltd., Dhaka, Bangladesh; Batch\# 7003; Exp. date: Sep'09) and Amoxil-Bencard $^{\circledR}$ (manufactured by Smith Kline Beecham plc, Middlesex, UK; Batch\# B.526003, Exp. date: 03-08-08) were used as test and reference product respectively for bioequivalence study.
Acetonitrile (Fisher Scientific, UK) and monobasic potassium dihydrogen phosphate (Merck, India) were purchased. All aqueous solutions and buffers were prepared using de-ionized and doubly distilled water from a Ultrapure water system, Arium ${ }^{\circledR} 611$ (Sartorius, Germany).

Subjects. Twenty-four healthy male volunteers with a mean age of 26.92 years (range, 23 to 34 years) and a mean body mass index of $23.09 \mathrm{~kg} / \mathrm{m}^{2}$ (range, 20.83 to $25.55 \mathrm{~kg}$ ) were enrolled into the study. The study was conducted in the Department of Clinical Pharmacy and Pharmacology, Faculty of Pharmacy, University of Dhaka. All volunteers had normal hematologic, renal, and hepatic laboratory parameters at screening. Electrocardiograms were performed at screening and were also found normal. Nobody received any concurrent medications, and all subjects were nonsmokers.

Exclusion criteria were as follows: hypersensitivity to any of the penicillins, presence or history of clinically significant disease, concomitant drug therapy of any kind, antibiotic treatment within 15 days prior to amoxicillin treatment, laboratory test results outside the acceptable range, participation in any other studies within 3 months prior to entry into the present study, and blood donation during the study period or within 3 months prior to the beginning of the study.

Study Design. This clinical study was designed as an open-label, single-dose, crossover study with two treatments to evaluate and compare the pharmacokinetics and bioavailability of AmoxilBenacrd $^{\circledR}$ (reference product) and SK-mox ${ }^{\circledR}$ (test product). A washout period of 7 days was observed between drug administrations. The study was conducted in accordance with the International Conference of Harmonization (ICH) guideline for Good Clinical Practice (GCP) and in compliance with the Declaration of Helsinki and its amendments. ${ }^{8,9}$ Clinical protocol (Informed consent, questionnaire, methods) was approved from Bangladesh Medical Research Council (BMRC) and each subject signed the consent form and filled the questionnaire prior to entry into the study. The volunteers were abstained 
from consumption of xanthene containing foods and beverages (chocolates, tea, coffee or coke) for $24 \mathrm{hr}$ before administration of the dose and were fasted overnight (at least $10 \mathrm{hr}$ ).

Drug administration and sample collection. Each volunteer received either SK-mox ${ }^{\circledR}$ (test product) or Amoxil-Benacrd ${ }^{\circledR}$ (reference product) along with $250 \mathrm{ml}$ of potable water after overnight fasting. A standard breakfast and standard lunch were provided after 4 and $7 \mathrm{~h}$ of sampling, respectively.

Urine samples were collected prior to drug administration considered as blank sample and then in block samples at $0-2,2-4,4-6,6-8,8-10$ and $10-12 \mathrm{hr}$ post dosing. The volume of urine, collected during each period from each volunteer, was measured. The urine samples were collected in coded eppendorf and kept at $-40^{\circ} \mathrm{C}$ until further analysis.

Preparation of urine sample for HPLC analysis. To $0.9 \mathrm{ml}$ of urine samples, $0.1 \mathrm{ml}$ of Cefaclor $(1 \mathrm{mg} / \mathrm{ml})$ was added as internal standard and vortexed for 15 seconds. Then $20 \mu \mathrm{l}$ of the samples was injected into the column after filtering through $0.2 \mu$ syringe filter to determine the concentrations of amoxicillin in urine samples using a validated HPLC method with UV detection.

Standard preparation. Stock solutions of amoxicillin $(1 \mathrm{mg} / \mathrm{ml})$ and cefaclor $(1 \mathrm{mg} / \mathrm{ml})$ were prepared by dissolving each of the accurately weighed reference compound in diluent (potassium dihydrogen phosphate, $\mathrm{pH}=5.0 \pm 0.05$ and acetonitrile at a ratio of 95:5). Calibration standards of $5,10,20,50,100,200,500 \mu \mathrm{g} / \mathrm{mL}$ for amoxicillin were prepared by serial dilutions of amoxicillin stock solution with blank urine and a fixed amount of cefaclor solution (internal standard). These samples were analyzed by the HPLC for the construction of calibration curve and method validation. Three levels of quality control working solutions, 5, 50 and 500 $\mu \mathrm{g} / \mathrm{ml}$, were also prepared which were used for precision, accuracy and stability testing. All working solutions were stored at $4^{\circ} \mathrm{C}$.
Chromatographic conditions. The Shimadzu (Tokyo, Japan) HPLC system consisted of a SCL10Avp system controller, two LC-8A pumps and a SPD-10Avp UV-VIS detector (Shimadzu Corporation; Tokyo, Japan). The sample analysis was conducted on a Nucleosil $\mathrm{C}_{18}$ column $(5 \mu, 4.6$ X 250 $\mathrm{mm}$, Varian, CA, USA), with a mixture of monobasic potassium phosphate buffer $(\mathrm{pH} 5.0 \pm 0.05)$ and acetonitrile (95:5), at a flow rate of $1.5 \mathrm{ml} / \mathrm{min}$. The effluent was monitored at $230 \mathrm{~nm}$. The drug analysis data were acquired and processed using LC solution (Version 1.03 SP3, Shimadzu Corporation, Tokyo, Japan) software running under Windows XP on a Pentium PC. Quantification of amoxicillin in urine samples was obtained by plotting amoxicillin to internal standard (cefaclor) peak area ratio as a function of amoxicillin concentration.

Method validation. Method validation was performed according to the protocol using a nominal concentration range of standards spanning from 5 to $500 \mu \mathrm{g} / \mathrm{mL}$ in urine to demonstrate the linearity, precision, accuracy, and stability of the method. Stability was confirmed for urine samples exposed to three freeze-thaw cycles, for samples stored for 48 hours at room temperature before injection, and for samples in long term storage at $-40^{\circ} \mathrm{C}$ for up to 1 month.

Pharmacokinetic analysis. Pharmacokinetic parameters were calculated by non-compartmental analysis, according to the standard method with the software Kinetica (Version 4.4.1, Thermo Electron Corporation, UK). ${ }^{10}$

For urine samples, the following input data were applied: start and end time of each urine collection interval $(\Delta \mathrm{t})$, urine concentrations $(\mathrm{C})$, and urine volumes (V) from which the midpoint of each collection interval and the renal excretion rate for each interval (R) was computed according to equation (I).

$$
\mathrm{R}=\frac{C V}{\Delta \mathrm{t}} \ldots \ldots \ldots \ldots(\mathrm{I})
$$

The maximal renal excretion rate $\left(R_{\max }\right)$ was observed and the midpoint of the respective collection interval associated with the maximal 
observed excretion rate $\left(t_{\max }\right)$ was also determined by visual inspection of the urinary excretion rate versus time profile curve. Area under the rate of amoxicillin excretion versus time curve $\left(\mathrm{AURC}_{0-t z}\right)$ was calculated according to the linear trapezoidal rule. The renal elimination rate constant $\left(\mathrm{K}_{\mathrm{el}}\right)$ was assessed by log-linear regression of the terminal segment of the excretion rate versus time curve and $\ln 2$ was divided by $\mathrm{K}_{\mathrm{el}}$ to calculate the terminal elimination half-life $\left(t_{1 / 2}\right){ }^{11}$ AURC $_{0-\infty}$ was determined by the following equation.

$$
\mathrm{AURC}_{0-\infty}=\mathrm{AURC}_{0-\mathrm{tz}}+\mathrm{R}_{\mathrm{tz}} / \mathrm{K}_{\mathrm{el}} \ldots \ldots \ldots \ldots \text { (II) }
$$

Moreover, the observed total amount of amoxicillin recovered in urine from 0 to $12 \mathrm{~h}\left(\mathrm{Ae}_{0-12}\right)$ and the fraction of orally administered amoxicillin excreted into urine within $12 \mathrm{~h}\left(\mathrm{f}_{\mathrm{e}} / \mathrm{f}\right)$ was calculated. The relative bioavailability was determined in terms of $\mathrm{AURC}_{0-48}, \mathrm{AURC}_{0-\alpha}$ and $\mathrm{Ae}_{0-12}$ from test formulation relative to reference formulation.

Statistical analysis. Student's t-test (paired) at $5 \%$ level of significance was used for testing the differences between the mean values obtained from two treatments using statistical software SPSS (Version 12.0, Chicago, IL). Pharmacokinetic parameters generated for the two treatments were also compared for significant differences due to dosing days (period effect), sequence (carryover effect), subjects within sequence, and formulation using ANOVA. ${ }^{12}$

Large sample based $90 \%$ confidence intervals were estimated for parameters like $\mathrm{R}_{\max }, \mathrm{Ae}_{0-12}$, $\mathrm{AURC}_{0-12}, \quad \mathrm{AURC}_{0-\alpha}$, for the assessment of bioequivalence according to FDA guideline.

\section{RESULTS AND DISCUSSION}

Method validation. The HPLC method with UV detection used for drug quantification provides the appropriated sensitivity, specificity. The experimental limit of quantification of the method was $0.1 \mu \mathrm{g} / \mathrm{ml}$, and the limit of detection was 0.05 $\mu \mathrm{g} / \mathrm{ml}$. Analysis of replicate blank serum samples indicated no interference peaks.
The calibration curve was linear over the concentration range of 5 to $500 \mu \mathrm{g} / \mathrm{ml}\left(\mathrm{r}^{2}>0.996\right)$. The intra-day accuracy of the method for amoxicillin in urine ranged from 100.40 to $106.34 \%$, while the intra-day precision ranged from 2.22 to $6.64 \%$. The absolute recovery of amoxicillin from urine was $97.69 \%$. No significant degradation of amoxicillin in urine, was observed during this period under the storage conditions.

Pharmacokinetic analysis. No clinical or biological side effects were reported during the study. The plots of mean percent of cumulative amount of amoxicillin excreted over a period of $12 \mathrm{~h}$ versus mid-point of time intervals and mean log of excretion rates versus mid-point of time intervals for all volunteers are shown in Figure 1 and Figure 2, respectively. From these figures, it is evident that both the formulations show similar excretion pattern, which in turn, indicates similarity in their bioavailability.

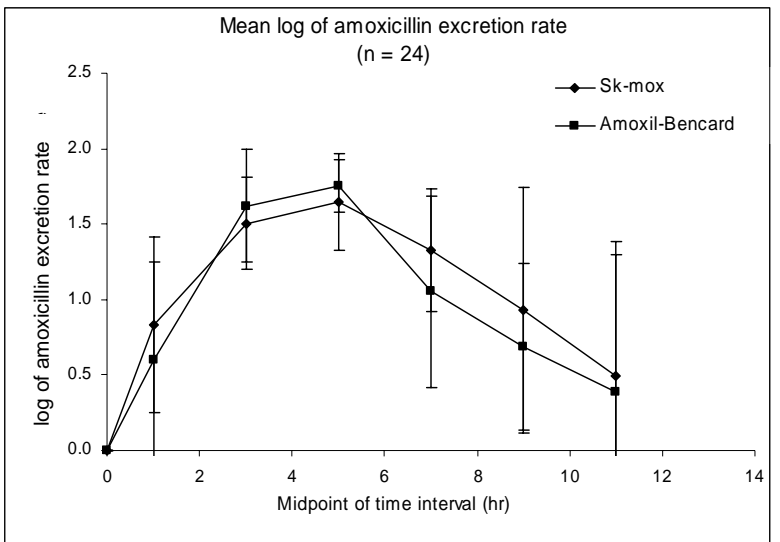

Figure 1. Mean percentage of cumulative amoxicillin excreted versus mid-point of time curve

Urinary recovery of amoxicillin from both formulations and statistical analyses are provided in Table 1. About $326.92 \mathrm{mg}(65.38 \%$ of dose) and $321.68 \mathrm{mg}(64.34 \%$ of dose $)$ of amoxicillin were excreted in $12 \mathrm{~h}\left(\mathrm{Ae}_{0-12}\right)$ after oral administration of test and reference formulations, respectively. Mean AURC $_{0-12}$ values were $311.21 \mathrm{mg}$ and $313.20 \mathrm{mg}$ for reference and test formulations, respectively. Maximum amount of amoxicillin excreted in respective time intervals $\left(\mathrm{R}_{\max }\right)$ for reference and test formulations was 73.82 and $70.43 \mathrm{mg} / \mathrm{hr}$, 
respectively. It was also observed that both the formulations showed maximum excretion rates in the interval of 5.5 and $4.83 \mathrm{hr}\left(\mathrm{t}_{\max }\right)$ in terms of mid-point of time (Fig. 2). Values of other pharmacokinetic parameters of test formulation were also comparable with that of reference formulation. The comparison of all these pharmacokinetic parameters indicates similar bioavailability of amoxicillin for test and reference formulations.

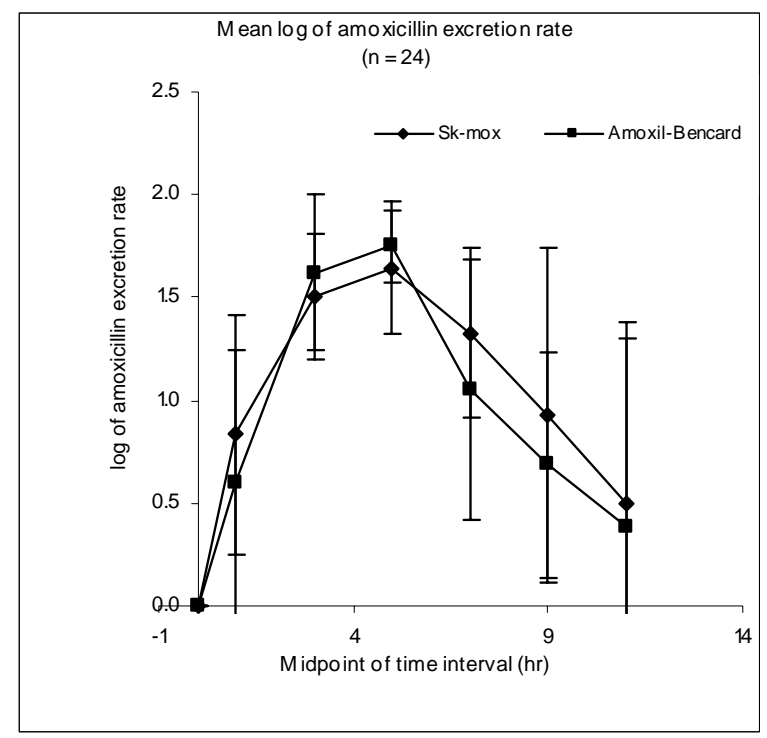

Figure 2. Mean log of amoxicillin excretion rate (R) versus midpoint of time plots for amoxicillin for all the volunteers after administration of both the formulations.
The relative bioavailability of amoxicillin from test formulation, in terms of $\mathrm{Ae}_{0-12}, \mathrm{AURC}_{0-48}$ and $\mathrm{AURC}_{0 \_}$a were found to be 101.63, 100.64 and $100.54 \%$, respectively. So the test product showed good bioavailability as compared to the reference one.

Statistical analysis for bioequivalence. No significant difference among the parameters was observed when analyzed by paired t-test at 5\% level of significance (Table 2). ANOVA assessment found no significant formulation, period or sequence effect in the present study (Table 3).

For bioequivalence decision, $\mathrm{R}_{\max }, \mathrm{Ae}_{0-12}$, $\mathrm{AURC}_{0-48}$ and $\mathrm{AURC}_{0-\alpha}$ values were taken into consideration for statistical analysis like 90\% confidence interval. The estimates of $90 \%$ confidence interval for the ratio of these four parameters were found to be within the specified limits of 80 to $125 \%$ for log-transformed data as per US FDA requirement for bioequivalence (Table 4) ${ }^{13}$ Thus, it is concluded that test formulation is bioequivalent to reference formulation.

Finally it can be concluded that the test (Sk$\operatorname{mox}^{\circledR}$ ) product is bioequivalent to reference (AmoxilBencard $^{\mathbb{B}}$ ) in terms of rate and extent of absorption and therefore interchangeable. Following administra-

Table 1. Mean urinary Pharmacokinetic Parameters of test (Sk-mox ${ }^{\circledR}$ ) and reference (Amoxil-Bencard ${ }^{\circledR}$ ) formulations

\begin{tabular}{|c|c|c|c|c|c|c|c|}
\hline \multicolumn{8}{|c|}{ Test Formulation $(n=24)$} \\
\hline $\begin{array}{l}\text { Pharmacokinetic } \\
\text { parameters }\end{array}$ & Mean & Median & $\begin{array}{c}\text { Geometric } \\
\text { Mean }\end{array}$ & SD & CV $(\%)$ & Max & Min \\
\hline $\mathrm{Ae}_{0-12}(\mathrm{mg})$ & 326.92 & 319.43 & 321.15 & 64.94 & 19.86 & 440.46 & 255.52 \\
\hline $\mathrm{R}_{\max }(\mathrm{mg} / \mathrm{hr})$ & 70.43 & 63.71 & 65.66 & 27.53 & 39.09 & 119.23 & 40.08 \\
\hline $\mathrm{t}_{\max }(\mathrm{hr})$ & 5.50 & 5.00 & 5.25 & 1.73 & 31.49 & 9.00 & 3.00 \\
\hline $\operatorname{AURC}_{0-12}(\mathrm{mg})$ & 313.20 & 307.73 & 307.01 & 66.06 & 21.09 & 436.50 & 237.92 \\
\hline $\operatorname{AURC}_{0-\infty}(\mathrm{mg})$ & 341.58 & 335.60 & 335.61 & 67.05 & 19.63 & 443.53 & 262.10 \\
\hline $\mathrm{K}_{\mathrm{el}}\left(\mathrm{hr}^{-1}\right)$ & 0.52 & 0.36 & 0.44 & 0.32 & 61.06 & 1.16 & 0.16 \\
\hline $\mathrm{t}_{1 / 2}(\mathrm{hr})$ & 1.84 & 1.91 & 1.57 & 1.07 & 57.88 & 4.21 & 0.60 \\
\hline $\mathrm{f}_{\mathrm{e}} / \mathrm{f}(\%)$ & 65.38 & 63.89 & 64.23 & 12.99 & 19.86 & 88.09 & 51.10 \\
\hline \multicolumn{8}{|c|}{ Reference Formulation $(\mathrm{n}=24)$} \\
\hline $\operatorname{Ae}_{0-12}(\mathrm{mg})$ & 321.68 & 300.16 & 312.09 & 87.17 & 27.10 & 521.17 & 217.27 \\
\hline $\mathrm{R}_{\max }(\mathrm{mg} / \mathrm{hr})$ & 73.82 & 71.45 & 69.08 & 29.70 & 40.23 & 138.51 & 43.18 \\
\hline $\mathrm{t}_{\max }(\mathrm{hr})$ & 4.83 & 5.00 & 4.65 & 1.34 & 27.66 & 7.00 & 3.00 \\
\hline $\mathrm{AURC}_{0-12}(\mathrm{mg})$ & 311.21 & 297.99 & 300.91 & 88.35 & 28.39 & 512.49 & 200.04 \\
\hline $\mathrm{AURC}_{0-\infty}(\mathrm{mg})$ & 339.75 & 306.14 & 331.63 & 81.48 & 23.98 & 513.27 & 238.72 \\
\hline $\mathrm{K}_{\mathrm{el}}\left(\mathrm{hr}^{-1}\right)$ & 0.42 & 0.29 & 0.28 & 0.34 & 80.99 & 1.23 & 0.01 \\
\hline $\mathrm{t}_{1 / 2}(\mathrm{hr})$ & 2.58 & 2.39 & 2.06 & 1.92 & 74.50 & 7.88 & 0.56 \\
\hline $\mathrm{f}_{\mathrm{e}} / \mathrm{f}(\%)$ & 64.34 & 60.03 & 62.42 & 17.43 & 27.10 & 104.23 & 43.45 \\
\hline
\end{tabular}

$\mathrm{Ae}_{0-12}=$ Cumulative amount of unchanged drug excreted within $12 \mathrm{hr} ; \mathrm{R}_{\max }=$ Maximum rate of excretion; $\mathrm{t}_{\max }=\mathrm{Time}$ of maximum rate of excretion; AURC $_{0-12} \&$ AURC $_{0-\infty}=$ Area under the rate of excretion versus midpoint of time interval curve for time 0 to 12 hr and up to infinity respectively; $\mathrm{K}_{\mathrm{el}}=$ Elimination rate constant; $\mathrm{t}_{1 / 2}=$ Elimination half-life; $\mathrm{f}_{\mathrm{e}} / \mathrm{f}=$ Fraction of unchanged drug excreted. 
Table 2. $P$-values for different pharmacokinetic parameters of two formulations calculated by Paired $t$-test $(n=24)$

\begin{tabular}{lcccccccc}
\hline Parameters & $\mathrm{Ae}_{0-12}$ & $\mathrm{R}_{\max }$ & $\mathrm{t}_{\max }$ & $\mathrm{AURC}_{0-12}$ & $\mathrm{AURC}_{0-\infty}$ & $\mathrm{K}_{\mathrm{el}}$ & $\mathrm{t}_{1 / 2}$ & $\mathrm{f}_{\mathrm{e}} / \mathrm{f}$ \\
\hline$P$-values & 0.73 & 0.43 & 0.22 & 0.877 & 0.929 & 0.357 & 0.205 & 0.73 \\
\hline
\end{tabular}

Table 3. $P$-values for sources of variations obtained from Analysis of Variance (ANOVA)

\begin{tabular}{lcccccccc}
\hline $\begin{array}{l}\text { Sources of } \\
\text { Variations }\end{array}$ & $\mathrm{Ae}_{0-12}$ & $\mathrm{R}_{\max }$ & $\mathrm{t}_{\max }$ & $\mathrm{AURC}_{0-12}$ & $\mathrm{AURC}_{0-\infty}$ & $\mathrm{K}_{\mathrm{el}}$ & $\mathrm{t}_{1 / 2}$ & $\mathrm{f}_{\mathrm{e}} / \mathrm{f}$ \\
\hline Formulation & 0.257 & 0.155 & 0.303 & 0.206 & 0.639 & 0.592 & 0.986 & 0.257 \\
Period & 0.519 & 0.327 & 0.252 & 0.606 & 0.842 & 0.211 & 0.242 & 0.519 \\
Sequence & 0.542 & 0.900 & 0.893 & 0.578 & 0.372 & 0.626 & 0.899 & 0.542 \\
Subjects & 0.001 & $<0.001$ & 0.079 & $<0.001$ & 0.031 & 0.188 & 0.097 & 0.001 \\
\hline
\end{tabular}

Table 4. Large sample based $90 \%$ Confidence Intervals for different pharmacokinetic parameters

\begin{tabular}{lccc}
\hline & \multicolumn{3}{c}{$90 \%$ Confidence Intervals } \\
\hline Parameters & Point estimate & Upper limit & Lower limit \\
\hline $\mathrm{R}_{\max }$ & 95.05 & 104.49 & 86.47 \\
$\mathrm{Ae}_{0-12}$ & 102.90 & 111.40 & 95.06 \\
AURC $_{0-12}$ & 102.03 & 109.52 & 95.05 \\
AURC $_{0-\infty}$ & 101.20 & 112.04 & 91.40 \\
\hline
\end{tabular}

tion of reference formulation, the cumulative urinary recovery of amoxicillin was found to be $64.34 \%$ over $12 \mathrm{hr}$ period in the present study. This recovery is higher compared to the studies on Chilies $(43.4 \%$ in $24 \mathrm{hr}$ ) and Americans (55.8\% in $12 \mathrm{hr})$; but lower than the Germans $(68 \%$ in $6 \mathrm{hr})$ and Pakistanis (73.3\% in $12 \mathrm{hr}$ ). ${ }^{14-17}$ In another study on Americans, the urinary recovery was found to be $70 \%$ in $6 \mathrm{hr}^{18}$ These variant recoveries of amoxicillin clearly reflect the ethnic variation in terms of rate and extent of amoxicillin metabolism and excretion, which could be a focus for further study. The exact mechanism of this variation may involve polymorphism of drug transporter, metabolic enzymes or altered drugprotein interaction. These differences in pharmacokinetics may cause some adverse effects in patients and this necessitates the importance of such study on Bangladeshi population to ensure safety and efficacy of this formulation.

\section{REFERENCES}

1. Suarez-Kurtz, G., Ribeiro, F.M., Vicente, F.L. and Strychiner, C.J. 2001. Development and Validation of Limited-Sampling Strategies for Predicting Amoxicillin Pharmacokinetic and Pharmacodynamic Parameters. Antimicrob. Agents Chemther. 45, 3029-3036.

2. Nathwani, D. and Wood M.J. 1993. Penicillins: a current review of their clinical pharmacology and therapeutic use. Drugs. 45, 866-894.

3. Paintaud, G., Alvan, G., Dahl, M.L., Grahnen, A., Sjovall, J. and Svenson, J.O. 1992. Nonlinearity of amoxicillin absorption kinetics in human. Eur. J. Clin. Pharmacol 43, 283-288.

4. Simon, C. and Stille, W. 1985. Antibiotikatherapie in Klinik und Praxis. Schattaur, NY, USA, 1985.

5. Barr, W., Zola, E.M. and Candle, E.L. 1994. Differential absorption of amoxicillin from the human small and large intestine. Clin. Pharmacol. Ther. 56, 279-285.

6. USP 24, NF 19: Asian ed. The United States Pharmacopeial Convention, Inc., 12601. Twinbrook Parkway, Rockville, MD, 2000, pp. 2056.

7. Shishoo, C.J., Shah, S.A., Rathod, I.S., Savale, S.S. and Vora, M.J. 2001. Impaired bioavailability of rifampicin in presence of isoniazid from fixed dose combination (FDC) formulation. Int. J. Pharm. 228, 53-67. 
8. European Agency for the Evaluation of Medicinal Products, International Conference on Harmonization - World Health Organization. Guideline for Good Clinical Practice [EMEA Web site]. ICH topic E6. Geneva, Switzerland: WHO; 2002; http://www.emea.europa.eu. Accessed January 10, 2008.

9. World Medical Association Declaration of Helsinki: Ethical Principles for Medical Research Involving Human Subjects [WMA Web site]. Adopted by the 18th WMA General Assembly, Helsinki, Finland, June 1964, and amended by the 52nd WMA General Assembly, Edinburgh, Scotland, October 7, 2000. http://www.wma.net/e/policy/b3.htm. Accessed January 10, 2008.

10. Gibaldi, M. and Perrier, D.: Pharmacokinetics. New York: Marcel Dekker, Inc., 1982.

11. Shah, S.A., Rathod, I.S., Savale, S.S. and Patel, D.B. 2002. Determination of bioequivalence of lomefloxacin tablets using urinary excretion data. J. Pharm. Biomed. Ana. 30, 1319-1329.

12. Azad, M.A.K., Ullah, A., Latif, A.H.M. and Hasnat, A. 2007. Bioequivalence and pharmacokinetic study of two oral formulations of ciprofloxacin tablets in healthy male volunteers. J. Appl. Res. 7, 50-157.

13. FDA. 2002. Bioavailability and Bioequivalence Studies for Orally Administered Drug Products-General Considerations. Draft Guidance. US Department of Health and Human Services, Food and Drug Administration, Center for Drug Evaluation and Research.
14. Arancibia, A., Guttmann, J., Gonzalez, G. and Gonzalez, C. 1980. Absorption and disposition kinetics of amoxicillin in normal human subjects. Antimicrob. Agents Chemther. 17, 199-202.

15. Philipson, A., Sabath, L.D. and Rosner, B.1975. Sequence Effect on Ampicillin Blood Levels Noted in an Amoxicillin, Ampicillin, and Epicillin Triple Crossover Study. Antimicrob. Agents Chemther. 8, 311-320.

16. Adam, D., Visser, I.D. and Koeppe, P.1982. Pharmacokinetics of Amoxicillin and Clavulanic Acid Administered Alone and in Combination. Antimicrob Agents Chemther. 22, 353-357.

17. Ahmad, M., Bukhari, N.I. and Akhtar, N. 2001. Disposition Kinetics of Amoxicillin from Urinary Excretion Data in Normal Human Volunteers in Pakistan. Kuwait Med. J. 33, 226-228.

18. Bodey, G.P. and Nance, J.1972. Amoxicillin: In Vitro and Pharmacological Studies. Antimicrob. Agents Chemther. 1, 358-362. 